\title{
Canine Streptococcal Toxic Shock Syndrome associated with Necrotizing Fasciitis: An Overview
}

\author{
Barkha Sharma*1, Mukesh Kumar Srivastava ${ }^{2}$, Ashish Srivastava ${ }^{2}$ and Rashmi Singh ${ }^{1}$ \\ 1.Department of Epidemiology and Veterinary Preventive Medicine, 2.Department of Veterinary Medicine, \\ Pandit deen Dayal Upadhyay Pashuchikitsa Vigyan Vishwavidyalaya Evam Go Anusandhan Sansthan \\ (DUVASU) Mathura, UP, 281001, India \\ * Corresponding author email: manubarkha@yahoo.com \\ Received: 18-09-2011, Accepted: 23-10-2011, Published Online: 21-01-2012 \\ doi: $10.5455 /$ vetworld.2012.311-319
}

\begin{abstract}
Canine Toxic Shock Syndrome (CSTSS) is a serious often fatal disease syndrome seen in dogs caused as a result of an infection caused by gram positive cocci of the family Streptococci. The main bacterium involved in the etiology of Canine Streptococcal Toxic Shock Syndrome is Streptoccoccus canis, which was discovered by Deveriese in 1986 and implicated as a cause of this disease syndrome in 1996 by Miller and Prescott. The clinical findings in this syndrome are very much similar to those seen in the infamous 'Toxic Shock 'caused by staphylococcal toxins in humans, especially females. Like in humans, the reason for emergence/reemergence of Canine Streptococcal Toxic Shock Syndrome (CSTSS) is unclear and very little is known about its transmission and prevention. The disease is characterized by multi systemic organ failure and a shock like condition in seemingly healthy dog often following an injury. In absence of proper and prompt diagnosis and subsequent treatment by injectable antibiotics and aggressive shock therapy, dog often succumbs to the disease within a few hours. The dog may have some rigidity and muscle spasms or convulsions and a deep unproductive cough followed by haemorrhage from nasal and mouth along with melena. On necropsy, these dogs show severe edema of the gastrointestinal tract, congestion of multiple organs, severe pulmonary congestion and evidence of thrombo embolism. Necrotizing fasciitis is a localized form of streptococcal infection seen as extensive soft tissue sloughing and necrosis along the fascial planes. No vaccination is available so avoidance of the probable causal factors mainly participation in community events, estrus, change of environment and shipping is the only way to keep pet dogs away from this disease.
\end{abstract}

Key Words: Canine Streptococcal Toxic Shock Syndrome (CSTSS), Streptococcus canis, Necrotizing Fasciitis (NF), multiorgan failure

To cite this article :

Sharma B, Srivastava MK and Srivastava A (2012) Canine Streptococcal Toxic Shock Syndrome associated with Necrotizing Fasciitis: An Overview, Vet. World. 5(5):311-319, doi: 10.5455/vetworld.2012.311-319

\section{Introduction}

Streptococci are a family of heterogenous group of gram positive bacteria which have been implicated in causing either localized or systemic infections in both humans and animals. Some strains rarely cause disease and are often found as commensal inhabitants of the skin and mucosal surfaces (oral, nasal, and intestine), while other strains are capable of causing serious or even life threatening infections.

In dogs, $S$. canis is an opportunistic pathogen, inhabiting vagina and anal mucosa and has been isolated from a variety of diseases including skin infections, infections of urogenital and respiratory tracts, otitis externa, septicemia, necrotizing fasciitis and streptococcal toxic shock syndrome (Bornand, 1992; Miller et al., 1996; DeWinter et al., 1999). S. canis also causes various infections in cats, including arthritis, wound infections, septicaemia and streptococcal toxic shock syndrome, and it can cause mastitis in cows (Iglauer et al., 1991; Hassan et al., 2005). Very few human infections with $S$. canis have been documented; However, human infections with this species may be underestimated because many clinical isolates are reported to only as "group G Streptococcus" or GGS. Syndromes that have been associated specifically with $S$. canis include septicaemia, meningitis and peritonitis (Bert and Lambert-Zechovsky, 1997; Takeda et al., 2001; Whatmore et al., 2001).

\section{History}

In the early 1990's, Streptococci (Group A, âhemolytic Strept) emerged as the cause of a previously unrecognized disease in humans and the disease came 
to be known as Streptococcal Toxic shock Syndrome because it closely resembled the spectrum of toxic shock caused by the better known "Toxic Shock" in women caused by a Staphylococcal toxin.

The bacterium, Streptococcus canis was described for the first time by Devriese in 1986 and it's role in causing a toxic shock like disease syndrome in dogs was described in 1996 by Miller and Prescott who reported on a series of seven dogs from southern Ontario, Canada that had severe systemic disease and shock associated with infection with â-hemolytic Streptococcus canis (Lance field Group G). Out of these seven dogs, four had associated necrotizing fasciitis. Since then, the disease has been reported in other dog breeds and is increasingly becoming a cause of concern for dog owners. Like in humans, the reason for the emergence/re-emergence of canine STSS/NF is unclear and very little is known about transmission or prevention.

Streptococcal Toxic shock Syndrome is a severe and often fatal disease characterized by shock and multiorgan failure. Both S.canis and S.equi subsp. zooepidemicus have been isolated from dogs with cases of Streptococcal Toxic shock Syndrome with $S$. canis being the major bacterium involved.

Necrotizing fasciitis ("flesh eating Strep") is a localized form of streptococcal infection characterized by rapidly advancing infection of subcutaneous tissues including muscle, fat and skin with extensive tissue destruction, severe local pain and high mortality rates.

\section{Etiology}

S.canis is the â-hemolytic Lancefield Group G streptococcus and is a commensal and opportunistic pathogen on the skin and mucosa of dogs and other species. S.equi subsp. zooepidemicus is also a âhemolytic Lancefield Group C bacteria and causes variety of infections in many species. These bacteria are gram positive cocci appearing in pairs or in chains forming circular colonies with entire edges on nutrient agar and uniform large wide zones of haemolysis on blood agar. All strains of S.canis are facultative anaerobes with good growth at $37^{\circ} \mathrm{C}$, catalase negative, produce acid, and give strong or weak reduction reactions in litmus milk. A precipitate is formed in broth cultures. They are not resistant to $6.5 \%$ sodium chloride solution or $40 \%$ bile. Guanine + Cytosine content of DNA ranges from 39 to $40 \mathrm{~mol} \%$. Most biotypes produce phosphatase, leucine arylamidase, arginine dihydrolase, alpha-D- and betaD-galactosidase and fermented lactose and ribose
(Lyskova et al., 2007). They fail to ferment sorbitol and are negative for hippurate, fibrinolysin, tyrosine, starch hydrolysis, Voges-Prauskauer and pyrrolidonnylarylamidase reactions (Devriese et al., 1986). Christine Atkinson Munch Peterson (CAMP) like reactions are present in around $60 \%$ strains. Since clonal expansion is thought to be partially responsible for the spread of invasive strains of S.pyogenes in humans, attempts were made to study the relatedness of S. canis isolates from CSTSS and NF using pulse field gel electrophoresis and biotyping, it was found that $S$. canis isolated from cases of CSTSS and/or NF in dogs were not clonally related (De Winter and Prescott, 1999). In contrast to this, pulsed field gel electrophoresis (PFGE) profile in feline isolates suggested a clonal origin (Kruger et al., 2010). S. canis has also been implicated in a case of fatal necrotizing fasciitis and myositis in a cat (Sura et al., 2008).

\section{Epidemiology}

The emergence of streptococcal toxic shock syndrome and necrotizing fasciitis caused by S.canis was reported by DeWinter \& Prescott in 1999 from Canada and USA after a series of seven dogs suffering with systemic infections caused by S.canis was reported by Miller and Prescott in 1996 from Southern Ontario, Canada. Since then, new more invasive strains of S.canis have emerged, resulting in frightening new diseases in dogs as well as humans and various other animal species. The disease syndrome is now well recognized and reported from all over the world with majority of cases reported from USA, Canada, Australia, Europe (Pesavanto et al., 2007; Sura et al., 2008; Lyskova et al., 2007; Lamm et al., 2010). The emergence of this disease has been attributed to the popularity of fluroquionolones for use in dogs. It has now been shown that enrofloxacin can cause a bacteriophage induced lysis of S.canis and superantigen expression (Ingrey et al., 2003) which induce T-cell proliferation and excessive release of host cytokines with potentially lethal effects.

\section{Host Susceptibility}

Although dogs are considered to be the main hosts for the disease, cases have occurred in cats (Sura et al., 2008, Taillefer et al., 2004 and Pesavento et al., 2007), horse (Dolente et al., 2000 ), in captive coyotes (Gates and Green, 1979) and in racing greyhounds (Sunderberg et al., 1981). Breeds of dogs like Chinese Sher pei, racing greyhounds, Great Dane etc seem to be particularly susceptible to CSTSS but cases have been increasingly reported in other breeds and the 
disease has become a concern for owners of dogs housed in large groups or those participating in shows or performance events.

\section{Zoonotic Potential}

Canine Streptococcal Toxic Shock Syndrome resembles a severe invasive group A streptococcal disease in humans also known as Streptococcal Toxic Shock caused by $S$. pyogenes which is also transferable to dogs although rarely. In people, $S$. canis has been isolated from cases of septicemia, localized soft tissue infections, UTIs and osteomyelitis (Galperine et al., 2007). Both S.canis and S.equi subsp. zooepidemicus are opportunistic pathogens that are zoonotic in nature, capable of causing severe invasive disease in domestic animals and humans. A SCM (S.canis Mlike) protein has been identified that binds human plasminogen and facilitates bacterial transmigration mediating the fibrinolytic activity of $S$. canis in humans (Fulde et al., 2011) Transmission of S.canis to humans seems to require a close contact and most cases, to date, were probably acquired by contamination of open wounds or dog bites. Practice of identifying streptococci only by the Lancefield serological group or biochemical tests may result in underestimation of the presence of $S$. canis in the human population as published biochemical description are inconsistent (Whatmore et al., 2001; Lam et al., 2007) .Also many clinical isolates are reported to only as 'Group G streptococcus' and are no further investigated. One case each of septicemia in humans have been reported by Takeda et al., 2001 and Bert and Lambert-Zechovsky, 1997, in a 75 year old women and 77 year old man caused by S. canis presumably after a dog bite and vicinity with a pet dog respectively. In another study, Group G streptococci were found in $16.67 \%$ of cases of human otitis externa by microbiological examination (Cristina and Degi., 2009 ). Three cases of ulcers in dog owners caused by S.canis have been described by Lam et al., 2007. Out of 92 patients with group $\mathrm{G}$ streptococcal bacterimia, one patient was identified with S.canis but with no history of dog bite (Liao et al., 2008).

\section{Mode of Transmission and Risk Factors involved}

The portal of entry in dogs usually seems to be the throat and lungs. Close physical contact with an infected but asymptomatic dog is reasonably safe but jaw-wrestling and play-fighting can transmit the infection. Sharing a run with an infected dog is an important risk factor, as well as water bowls, bedding etc. The reproductive tract of bitches in season is an open invitation to bacteria as licking of genitalia of bitch in season by infected male is a important risk factor. Dogs licking the face of humans with a streptococcal throat or cellulites or of a child with impetigo are definitely at risk. Crowded conditions and dog shows especially indoors and in fall and winter months increase the risk of disease transmission. Also handlers and judges may transmit the infection by examining, handling multiple dogs sequentially without washing their hands .Stress factors as traveling long distances, confinement, exposure to stressful conditions, estrus may reduce a dog's resistance to the disease. Healthy adult dogs are not as susceptible to streptococcal infections as younger or older dogs are. This may be because a young dog's immune system may be less effective than that of a healthy adult.

\section{Pathogenesis}

Streptococcal infection is a rapidly progressing, highly invasive process leading to STSS, a shock like syndrome, multiorgan failure and necrotizing fasciitis. Not much is known about its pathogenesis and protective immune mechanism. Pyrogenic exotoxins cause fever in humans and animals and also help to induce shock by lowering the threshold to exogenous endotoxins (Dillon, 1968). Streptococcal pyrogenic exotoxins A and B induce the production of Tumor necrosis factor-á (TNF á) (Fast et al., 1989) and interleukin-1â (IL-1 â) and interleukin-6 (IL-6) (Hackett et al., 1991) suggesting that TNF could mediate the fever, shock, and tissue injury in case of STSS. Streptococcus canis is a potent producer of exotoxin which may be responsible for the rapid progression of sepsis, shock and multiorgan failure in case of CSTSS.

In people, the clonal expansion of invasive strains of S.pyogenes is thought to promote the development of toxic shock syndrome but this does not appear to be the case in the dogs. Furthermore, proteins from the $S$. canis isolates from the cases of NF have homology with only 2 proteins (M protein and Streptolysin O) of the 10 known virulence factors of invasive S.pyogenes (DeWinter et al., 1999).This finding suggests that yet another unknown factors are involved in the pathogenesis of S.canis toxic shocklike syndrome in dogs. M proteins contribute to invasiveness through its ability to impede phagocytosis of streptococci by polymorphonuclear leukocytes (Lancefield, 1962). Data suggest that the streptococcal exotoxin and a number of staphylococcal toxins can 
stimulate T-cell responses through their ability to bind to both Class II major histocompatibility complex of antigen presenting cells and the $\mathrm{V}_{\hat{\mathrm{a}}}$ region of the $\mathrm{T}$-cell receptor (Mollick and Rich, 1991). The net effect would be to induce T-cell stimulation with the production of cytokines capable of mediating shock and tissue injury. Peptidoglycan, lipoteichioc acid (Stevens et al., 1992), and killed organisms (Hackett et al., 1991; Muller et al., 1994.) are capable of inducing TNFá production by mononuclear cells in vitro (Wannamaker et al., 1951; Muller et al., 1994; Hackett et al., 1994). Exotoxins such as streptolysin O (SLO) are also potent inducers of TNFá and pre-Interleukin (IL)-1 â to release preformed IL-1 â (Kappur et al., 1993). Whatever the mechanisms, induction of cytokines in vivo is likely the causes of shock and exotoxins, cell wall components, and the like, are potent inducers of TNF and IL-1.

Some investigations have attributed the virulence of the bacteria and more specifically fasciitis to expression of bacterial enzymes such as hyaluronidase which degrades the fascia (Stevens et al., 1995). Development of TSS is dependent on the presence of superantigens (Sags) in Streptococci. In humans, STSS and NF associated with $S$. pyogenes isolates possessing lysogenic bacteriophage-encoded superantigen genes, are thought to be crucial in the development of the disease (Cunningham, 2000; Goshorn and Schlievert, 1989; Kaul et al., 1997; McShan, 2000; Stevens et al., 1989; Yu and Ferati, 1991). These superantigens are powerful inducers of T-cell proliferation and cause the release of massive amounts of host cytokines with sometimes lethal effects (Fleischer, 1995; Kotb, 1995). Investigators attempting to identify superantigen genes in $S$. canis by DNA hybridization analysis using various S.pyogenes superantigen genes found that S.canis lacked genes with significant homology to the probes (De Winter et al., 1999). Recently the presence of Sag gene smeZ was detected in a human S.canis isolate although examination of isolates from dogs with TSS or NF has failed to detect the presence of Sag genes (DeWinter et al, 1999; Igwe, 2003 and Miller et al., 1996). A complete understanding of how S.canis causes invasive disease would include analysis of the genetic diversity among these isolated species (Pesavanto et al., 2007). It is assumed that S.canis contains many virulence characteristics of Group A Streptococcus (GAS) including an M type protein (Collins et al., 1992), hemolysins and erythrogenic toxins, but lacks some of the other recognized virulence genes with significant homology to those in S.pyogenes (DeWinter et al., 1999).

\section{Clinical Findings}

Canine streptococcal toxic shock syndrome has generated a great deal of concern among dog owners. Severe symptoms typical of CSTSS seem to result when the bacteria invade the blood stream, inducing septicemia and toxemia with a cascade of toxins.

Dogs that develop Canine streptococcal toxic shock syndrome are healthy only hours prior to becoming very sick. Pain is the most common initial symptom and is abrupt in onset and severe, and usually precedes tenderness or physical findings. Without a prompt therapy, the dog's condition deteriorates very rapidly with death occurring within eight to twelve hours. Typically, dogs that develop CSTSS are depressed and too weak to move, experience rigidity and spasms of muscle coupled with a high fever $\left(105^{\circ}\right.$ $\left.\mathrm{F}-107^{\circ} \mathrm{F}\right)$. As the disease progresses, a deep, non productive cough develops, followed by a rapid onset of spontaneous hemorrhaging like hemoptysis, epistaxis, hematuria, melena and ecchymoses of skeletal muscles. There are evidences of hypotensive shock with involvement of atleast one other organ or system (Prescott et al., 1997). In generalized systemic form, there is much more rapid onset with shock like condition like hypotension, severe weakness, rapid heart rate, pale mucous membrane, extreme pain, collapse, coma and acute death. Many dogs develop disseminated intravascular coagulation (DIC) which rapidly leads to multiple organ dysfunction syndrome (MODS).There is severe edema of the gastrointestinal tract (GIT), congestion of multiple organs, including lungs and evidence of thromboembolism, all pointing to shock due to sepsis or toxemia.

\section{Necrotizing Fasciitis}

Necrotizing fasciitis, a deep seated infection of the subcutaneous tissue that progressively destroys fascia and fat. A diagnosis of NF is made if there is either histopathologic or surgical evidence of superficial fascial oedema and necrosis. Most dogs with NF also showed serious systemic disease including hypotension and sepsis.

Prescott et al., (1997) reported 14 cases of canine STSS and NF in 1992 from Ontario, Canada having typical signs of STSS although one dog also had signs of spinal cord involvement. Out of 14, 8 dogs had associated NF. A consistent sign in all cases of NF was intense pain. Localized heat and swelling were identified within 48 hours of presentation. All dogs with NF had extensive accumulation of exudate along the fascial planes.

Necrotizing fasciitis is the localized form of 
streptococcal infection. Dogs with NF have high rectal temperature and tend to develop extensive soft tissue sloughing of the underlying fatty tissue; hence it has been called 'flesh eating bacteria'. Areas most commonly involved are hock joints, flanks and the abdominal skin. There is pus discharge from affected areas which is very painful to touch.

\section{Clinical course}

Mortality rate normally exceeds $70-80 \%$ as the course of disease is so rapid that a dog may succumb to it in as little as 1to 4 hours from the appearance of the first signs, so that some dogs are simply found dead in their runs, houses or yards.

\section{Post mortem Lesions}

Canine Toxic shock syndrome and/or necrotizing fasciitis resemble the toxic shock syndrome in people infected with S.pyogenes. On postmortem, affected dogs typically have deep dermal or subcutaneous lesions along the limbs or trunk. Involvement of multiple organ system suggests a period of septicemia before the development of this syndrome (Prescott and De Winter, 1997). Most dogs die without developing any significant postmortem lesions. In a finding, most significant pathologic lesion was a suppurative and haemorrhagic broncho-pneumonia with focal areas of bronchiolar epithelial ulceration, superimposed on lesions of chronic bronchiectesis along with widespread vascular congestion affecting all solid organs (Prescott et al., 1995). Dogs with NF have extensive accumulation of exudates along with necrotic fascial planes.

\section{Diagnosis}

Diagnosis is based on the history of previous trauma, typical clinical signs, bacterial culture and sensitivity of discharges of the affected tissue samples. In most cases, there is history of sudden development of clinical signs like intense pain, fever with lateral recumbancy, rapid spontaneous hemorrhages associated with hemoptysis, epistaxis, severe bruising of skin and in some cases, bloody diarrhea. There may be hypotension, multiorgan failure and quick death especially without proper treatment. Isolation and identification of Gram positive cocci in pairs or chains from clinically relevant, normally sterile sites (infected smears, tissues or aspirates), usually in pure culture gives a definite diagnosis. Bacteria may also be found in wounds, blood, secretions, pus or other sites.

Streptococcus can be identified by their haemolytic pattern on blood agar, colony morphology, biochemical reactions and serology.
S.canis is a beta haemolytic streptococci which usually produce phosphatase, leucine amidopeptidase, arginine dihydrolase, alpha-D-and beta-D-galactosidase and ferment lactose and ribose. It also produces a CAMP like reaction on sheep blood agar after 24 hour incubation (Lyskova et al., 2007; DeWinter and Prescott, 1999).Genetic methods like DNA-DNA reassociation procedures, Pulse Field Gel Electrophoresis and $16 \mathrm{~s} r$ RNA gene sequencing can also be used for diagnosis. Serologic tests include Anti Streptolysin $\mathrm{O}$ (ASO) titer, anti-hyaluronidase titer and anti DNAseB.

Veterinarians should consider possible CSTSS when the clinical signs, including pain are out of proportion to the injury sustained or a predisposing medical problem. Rapid deterioration, marked pain and/or discomfort, with or without severe tissue swelling are consistent findings in these dogs. A diagnosis of STSS should be made if a dog has hypotensive shock and shows involvement of at least 1 other organ or system along with isolation of a Lancefield Group G streptococcus, usually in pure culture from infected site. A diagnosis of NF is made if there is either histopathologic evidence of necrosis of the fascial planes and tissues, and if a Group G streptococcus in pure culture is isolated from this site as well.

\section{Treatment}

Treatment needs to be started as early as possible in order to have any chance of saving the affected dog. The prognosis for systemic STSS must be considered very poor and dogs often succumb even after a heroic effort at the treatment. Those dogs who survive have been treated with intravenous antibiotics to which streptococci are susceptible, particularly to penicillin $\mathrm{G}$ and Clindamycin and shock therapy may include volume resuscitation, vasopressors, extensive surgical debridement of fascial planes and open wound management with daily irrigation of antibiotics (Prescott et al., 1995). One important point to be considered is that organism is often resistant to enrofloxacin and aminoglycosides therefore multiple antibiotic therapies with agents such as cephalexin, clindamycin, lincomycin, erythromycin and potentiated sulfas should be considered. The best approach is based on sensitivity information from a culture but that will take some time to generate.

In a study, the antimicrobial sensitivity tests showed that all isolates of S.canis were sensitive to penicillin $\mathrm{G}$ and ampicillin and the least effective antimicrobial agent was tetracycline (only $33.8 \%$ of susceptible strains). The respective rates of resistance 
to vancomycin, chloramphenicol, erythromycin and clindamycin were $10.5 \%, 7 \%, 3.5 \%$ and $2.3 \%$ respectively (Lyskova et al., 2007).

Early recognition, a correct diagnosis and prompt treatment is essential. Dogs treated with the correct injectible antibiotics at the early stages of the condition are more likely to recover. Treatment of cases with NF will improve with debridement or clearing away of the dead tissue, but healing is prolonged and skin grafts are often necessary. Long term management is intense with frequent bandage changes, cleaning of the wounds, antibiotic therapy and the need for multiple anesthetic procedures to repair and reconstruct the damaged areas most often hock joints, the flanks and the abdominal skin.

In a mouse model of myositis caused by $S$. pyogenes, penicillin was ineffective when treatment was delayed $>2 \mathrm{hrs}$ after initiation of infection (Stevens et al., 1988). Survival of erythromycintreated mice was greater than that of both penicillintreated mice and untreated controls, but only if treatment was begun within 2hours. Mice receiving Clindamycin, however, had survival rates of $100 \%$, $100 \%, 80 \%$ and $70 \%$ even if treatment was delayed $0,2,6$ and 16.5 hours, respectively (Stevens et al., 1995; Stevens et al., 1994).

Beta-Lactum failure has been reported in treating pharyngitis caused by Group $\mathrm{G}$ streptococcus (Savini et al., 2008). Evidence of invitro vancomycin tolerance was also reported by Zoutis et al., (1999) by group $\mathrm{C}$ and group $\mathrm{G}$ streptococci isolated from patients with invasive infections. These authors have also suggested that among high risk patients with invasive GCS and GGS infections who can't be treated with penicillin, tolerance of other antibiotics, including vancomycin, should be closely monitored and a combination therapy for synergy (Aminoglycosides and a cell wall active agent) in the initial treatment of these patients should be adopted.

Though antibiotic selection is critically important, other measures, such as prompt and aggressive exploration and debridement of suspected deep-seated wounds are mandatory. Fever is the most frequent finding along with excruciating pain. Later systemic toxicity develops, and evidence of necrotizing fasciitis and myositis may appear. Surgical debridement may be too late at this point. Neutralization of circulating toxins should be the main consideration. Two reports describe successful use of intravenous gamma globulins in treating streptococcal TSS in humans (Barry et al., 1992; Yong, 1994).

Prompt surgical incision with visualization of muscle and fascia, and timely Gram staininig of surgically obtained material may provide an early and definite etiologic diagnosis in order to initiate correct treatment procedure.

Alongside this allopathic line of treatment, alternative therapeutic approaches including homeopathic medicines like CARBO VEG.IM at 10-15 minutes intervals and ARNICA can be given to the dogs identified with CSTSS.

\section{Control and Prevention}

The threat of canine streptococcal toxic shock syndrome and NF has been increasingly becoming a serious threat to dogs and dog owners as well as veterinarians. Reported cases of canine CSTSS and NF have increased since 1995 in Northern America especially Canada though not much data is available from Indian subcontinent regarding the status of this syndrome.

For effective control of CSTSS and NF, factors contributing to its spread must be understood as an important pathogen causing fatal diseases. Popularity of fluroquinolones especially enrofloxacin for use in dogs has been associated with the emergence of CSTSS by S.canis (Miller et al., 1996). Enrofloxacin causes a bacteriophage induced lysis of S.canis and superantigen expression which might result in the spread of virulent gene into other bacteria thereby contributing to emergence of the pathogen ((Ingrey et al., 2003).

There are no commercial vaccines. Stress factors, such as travelling long distances, confinement, exposure to stressful situations; estrus etc may decrease a dog's resistance to disease. Dog equipments should be kept clean and not shared by multiple dogs. The reproductive tract of bitches in season is an open invitation to bacteria as well so it is advisable to spay or neuter companion animals. Wounds should be kept clean and good hygiene should be practiced. Biting, fighting, taking part in dog shows and other community activities increase the risk of illness. Also overgrown nails and teeth pose a threat.

S.canis or S.equi subsp zooepidemicus are a part of the normal flora in some species so it is very difficult to control the infections caused by them. Only factors leading to development of the disease condition can be understood and avoided. Dogs should be made to avoid high risk condition.

\section{Future Prospects}

A new streptococcal protective antigen SPA of S.canis (SPASc) has been recognized and this might 
have implications for the development of vaccines that would prevent the infections (Yang et al., 2010).

The availability of aminoacid sequence of SPASc now makes it possible to study its new role in virulence and pathogenesis and on the epitopes and domains of protein relevant to opsonic and protective responses. These studies suggest that SPASc might be an important component of vaccines to prevent S.canis infection.

Unfortunately, to date, advances in detection and prevention have been few. Vaccine development is also difficult because of the toxins interference with the ability of the immune system to function properly. No line of treatment has been found to be very effective in preventing the infection and no test has been beneficial at identifying those animals at risk.

Increased owner awareness, rapid initiation of appropriate antibiotic therapy and intensive support care are the keys to survival in this condition. Even an hour can make all the difference.

\section{References}

1. Barry, W., Hudgins, L., Donta, S.T. and Pesanti, E.L. (1992). Intravenous immunoglobulin therapy for toxic shock. JAMA 267(24): 3315-3316.

2. Bert, F. and Lambert-Zechovsky, N. (1997). Septicemia caused by Streptococcus canis in a human. J.Clin Microbiol.,35: 777-779.

3. Bornand, V. (1992). Bacteriology and mycology of otitis externa in dog. SchweiszArch Tierheilkd, 134: 341-348.

4. Collins, C.M., Kimura, A., Bisno, A.L. (1992). Group $\mathrm{G}$ streptococcal $\mathrm{M}$ protein exhibits structural features analogous to those of cliss $1 \mathrm{M}$ proteins of group A streptococci. Infect Immunol. 63: 994-1003.

5. Cunningham, M.W.(2000). Pathogenesis of group A streptococcal infections. Clin. Microbiol. Rev. 13: 470-511.

6. Cristina, R.T. and Degi, J. (2009). Zoonotic risk of some pathogenic agents involved in the dog's external otitis. Ist Joint Workshop of ASMM and ASAC. Vienna, 04-05.

7. Devriese, L.A., Jozef, H.,Klipper-Balz, R. and Schleifer, K.(1986). Streptococcus canis sp.nov.: a species of Group G Streptococci from animals. Int. J. Systemic Bacteriol.36 (3): 422-425.

8. Dewinter, L.M. and Prescott, J.F. (1999). Relatedness of streptococcus canis from canine Streptococcal Toxic shock syndrome and Necrotizing Fasciitis. Can J. Vet. Res., 63: 90-95.

9. DeWinter, L.M., Low, D.E., Prescott, J.F. (1999). Virulence of Streptococcus canis from canine streptococcal toxic shock syndrome and necrotizing fasciitis. Vet. Microbiol. 70: 95-110.

10. Dillon, H.C. (1968) Impetigo contagiosa: suppurative and non-suppurative complication. Clinical, bacteriologic and epidemiologic characteristics of impetigo.Am.J.Dis. Child.115:530-541.

11. Fast, D.J., Schlievert, P.M, Nelson, R.D.(1989) Toxic shock syndrome associated staphylococcal and streptococcal pyrogenic toxins are potent inducers of tumor necrosis factor production. Infect. Immun. 57: 291-294.

12. Fleischer, B. (1995). Bacterial superantigens. Rev. Med. Microbiol. 6: 49-57.

13. Fulde, M., Rohde, M., Hitzmann, A., Preisner, K.T. Nitche-Schmidt, D.P., Nerlich, A., Chhatwal, G.S. and Bergmann, S. (2011).SCM, a novel M-like protein from Streptococcus canis, binds (mini)-plasminogen with high affinity and facilitates bacterial transmigration. Biochem. J., 434:523-535.

14. Galperine, T., Cazorola, C., Elodie, B. et al., (2007) Streptococcus canis infections in humans: retrospective study of 54 patients. Jof Inf., 55: 23-26.

15. Garnett, N.L., Eydelloth, R.S., swindle, M.M., Vonderfcht, S.L., Strandberg, J.D., Luzarraga, M.B. (1982). Hemorrhagic streptococcal pneumonia in newly procured research dogs. J.Am.Vet.Med.Assoc., 181(1): 1371-1374.

16. Gates, N.L. and Green, J.S. (1979). Epizootic streptococcal pneumonia in captive coyotes. J. Wild Dis., 15(4): 497-498.

17. Goshorn, S.C. and P.M.Schlievert. (1989). Bacteriophage association of streptococcal pyrogenic exotoxin type C. J. Bacteriol. 171:3068-3073.

18. Hackett, S., Ferreti, J., Stevens, D. (1994). Cytokine induction by viable group A streptrococci:suppression by streptolysin O. Presented at the $93^{\text {rd }}$ Conference of the American Society for Mocrobiology, Las Vegas, NV, Abstract B-249.

19. Hackett, S.P., Schlievert, P.M., Stevens, D.L. (1991).Cytokine production by human mononuclear cells in response to streptococcal exotoxins. Clin. Res. 39: 189A.

20. Hassan, A.A., Akineden, O. and Usleber, E. (2005). Identification of Streptococcus canis isolated from milk of dairy cows with subclinical mastitis. J.Clin. Microbiol., 43: 1234-1238.

21. Iglauer, F., Kunstyr, I., Morstedt, R., Farouq, H, Wullenweber, M., Damsch,S. (1991). Streptococcus canis arthritis in a cat breeding colony. J. Exp. Anim. Sci.,34: 59-65.

22. Igwe, E.I., Shewmaker, P.L., Facklam, R.R., Farley, M.M., VanBeneden, C., Beall, B. (2003). Identification of superantigen genes speM, ssa, and smeZ in invasive strains of beta-hemolytic group $\mathrm{C}$ and $\mathrm{G}$ streptococci receovered from humans. FEMS Microbiol. Lett., 229: 259-264.

23. Ingrey. K.T., Ren, J. and Prescott, J.F. (2003). A fluoroquinolone Induces a Novel Mitogen-Encoding bacteriophage in Streptococcus canis. Infection and Immunity. 71(6);3028-3033.

24. Kappur, V., Majesky, M.W., Li, L.L., Black, R.A., Musser, J.M. (1993). Cleavage of interleukin 1B 
(1L-B) precursor to produce active IL-1 B by a conserved extracellular cysteine protease from Streptococcus pyogenes. Proc. Natl. Acad. Sci. USA. 90: 7676-7680.

25. Kaul,R.,A. McGeer, D. E. Low, K. Green, B. Schwartz, and A.E. Simor. (1997). Population based surveillance for group A streptococcal necotizing fasciitis: Clinical features, prognostic indicators, and microbiology analysis of seventy seven cases. Am.J. Med. 103: 18-24.

26. Kotb, M. (1995). Bacterial pyrogenic exotoxins as superantigens. Clin. Microbiol.Rev. 8:11-426.

27. Kruger, E.F., Byrne, B.A., Pesavento, P., Hurley, K.F., Lindsay, L.L. and Sykes, J.E. (2010). Relationship between clinical manifestations and pulsed-field gel profiles of Streptococcus canis isolates from dogs and cats.

28. Lamm, C.G., Ferguson, A.C., Lehenbauer, T.W. and Love, B.C. (2010). Streptococcal infection in dogs: A Retrospective Study of 393 Cases. Vet. Pathol. 47(3). 387-395.

29. Lam., M.M., Clarridge, J.E. $3^{\text {rd }}$, Young, E.J. (2007). The other Group G streptococcus: increased detection of Streptococcus canis ulcer infections in dog owners. J. Clin. Microbiol. . 45: 503-510.

30. Lancefield, R.C. (1962). Current knowledge of type specific M antigens of group A streptococci. $J$. Immunol.89: 307-313.

31. Liao C-H, Liu L-C, Huang Y-T, Teng L-J, Hsueh P-R. (2008). Bacteremia caused by group G streptococci, Taiwan. Emerg Infect Dis. 14(5).

32. Lyskova, P., Vydrzalova, M.,Kralocova and Mazurova, J. (2007). Prevalence and characteristics of Streptococcus canis Strains isolated from Dogs and Cats. Acta Vet. Brno. 76: 619-625.

33. McShan, W.M.(2000). The bacteriphages of group A streptococci, p.105-116. In V.A. Fishetti, R.P. Novick, J.J. Ferreti, D.A. Portnoy, and J.I. Rood (ed.), gram positive pathogens, ASM Press, Washington, D.C.

34. Miller, C.W., Prescott, J.F., Mathews, K.A., Betschel, S.D., Yager, J.A., Guru, V., DeWinter, L., Lowe, D.E. (1996). Streptococcal Toxic Shock Syndrome in dogs. J. Am. Vet. Med. Assoc., 209: 1421-1426.

35. Mollick, J.A. and Rich, R.R. (1991). Characterization of a superantigen from a pathogenic strain of streptococcus pyogenes. Clin. Res. 39: 213A.

36. Muller-Alouf, H., Alouf, J.E., Gerlach, D.M., Ozeegowski, J.H., Fitting, C., Cavaillon, J.M. (1994). Comparative study of cytokine release by human peripheral blood mononuclear cells stimulated with streptococcus pyogenes superantigenic eryhthrogenic toxins, heat killed streptococci and lipopolysaccharide. Infect Immun; 62: 4915-21.

37. Pesavanto, P.A., Bannasch, M.J., Bachman, R., Byrne, B.A. and Hurley, K.F. (2007). Fatal Streptococcus canis Infections in Intensively Housed Shelter cats. Vet. Pathol. 44(2);218-221.

38. Prescott J.F. and De Winter, L. (1997). Canine streptococcal toxic shock syndrome and necrotizing fasciitis. Vet Rec. 140: 263.

39. Prescott, J.F., Mathews, K A., Gyles, C.L., et al. (1995). Canine streptococcal toxic shock syndrome in Ontario: An emerging Disease. Can. Vet J. 36: 486487.

40. Prescott, J.F.Miller, C.W., Mathews, K.A.Yager, J.A., DeWinter, L. (1997). Update on canine streptococcal toxic shock syndrome and necrotizing fasciitis. Can Vet. J., 38: 241-242.

41. Savini, V., Catavillo, C., Talia, M., Manna, A.,Pompetti, F., Bonaventura, G.D., Giuseppe, N.D., Febbo, F., Balbinot, A., Zacomo, S.D., Esattore, F and D'Antonio, D. (2008). â-lactum Failure in Treatment of Two Group G Streptococcus dysgalactiae subsp equisimilis Pharyngitis patients. J. Clin.Microbiol. 46(2): 814-816.

42. Stevens, D.L, Tanner, M.H. Winship, J. R. Swarts, K.M., Ries, P.M., Schlievert, and Kapland, E.(1989) Severe group A streptococcal infections associated with a toxic shock-like syndrome and scarlet fever toxin. N.Eng.J.Med.321: 1-7.

43. Stevens, D.L. (1995). Streptococcal Toxic-Shock Syndrome: Spectrum of Disease, Pathogenesis, and New Concepts in Treatment. Emerging Infectious Diseases, 1 (3): 69-78.

44. Stevens, D.L. (2000). Streptococcal Toxic shock Syndrome Associated with Necrotizing Fasciitis Annu. Rev. Med.51:271-288.

45. Stevens, D.L., Bryant, A.E. and Hackett, S.P. (1992). Gram-positive shock. Curr Opin Infect Dis.,5:355-63.

46. Stevens, D.L., Bryant, A.E. and Hackett, S.P. (1995) Antibiotic effects on bacterial viability, toxin production and host response. Clin Inf Dis, 20 (Suppl 2) S154-157.

47. Stevens, D.L., Bryant, A.E. and Yan, S. (1994). Invasive Group A streptococcal infection: new concepts in antibiotic treatment. Int. J. Antimicrob. Agents.4: 297-301.

48. Stevens, D.L., Gibbons, A.E., Bergstrom, R., Winn, V. (1988). The eagle effect revisited: efficacy of clindamycion, erythromycin and penicillin in the treatment of streptococcal myositis. J Infect Dis, 158: 23-8.

49. Sundberg, J.P., Hill, D., Wyand, D.S., Baldwin, C.H (1981). Streptococcus zooepidemicus as the cause of septicemia in racing greyhounds. Vet. Med. Small Anim. Clin. 76(6): 839-842

50. Sura, R., Hinckley, L.S., Risatti, G.R. and Smyth, J.A. (2008). Fatal Necrotising fasciitis and myositis in a cat associated with Streptococcus canis. Vet. Rec. 162: 450-453.

51. Taillefer, M. and Dunn, M. (2004). Group G Streptococcal Toxic Shock Like Syndrome in three cats. J. Am. Anim. Hospital. Assoc., 40:418-422.

52. Takeda, N., Kikuchi, K., Asano, R., Harada, T., Totsuks, K., Sumiyoshi, T., Uchiyama, T and Hososda, S. (2001). Recurrent septicemia caused 
by Streptococcus canis after a dog bite. Scand. J. Infect. Dis., 33: 927-928.

53. Wannamaker, L.W., Rammelkamp, C.H. Jr.,Denny, F.W., Brink, W.R., Houser, H.B., Hahn, E.O. et al. (1951) Prophylaxis of acute rheumatic fever by treatment of the preceeding streptococcal infection with various amounts of depot penicillin. Am. J. Med. 10: 673-695.

54. Whatmore, A.M., Engler, K.H., Gudmundsdottir, G., Efstratiou, A. (2001). Identification of isolates of Streptococcus canis infecting humans, J. Clin. Microbiol., 39: 4196-4199.

55. Yang, J.,Yanfei, L., Xu, J., Li, B. (2010). Characterization of a new protective antigen of Streptococcus canis. Vet.Res. Commun. 34: 413-421.

56. Yong, J.M. (1994). Letter. Lancet.343: 1427.

57. Yu, C.E. and Ferratti, J.J. (1991). Molecular characterization of new group A streptococcal bacteriphages conataining the gene for streptococcal erythrogenic toxin A (speA). Mol. Gen. Genet. 231: 1161-168.

58. Zoutis, T., Schneider, B., Moore, L.S. and Klein, J.D. (1999). Antibiotis Susceptibilities of Group G and Group C Streptococci isolated from Pateints with Invasive Infections: Evidence of Vancomycin Tolerance among Group g Serotypes. J Clin. Microbiol. 37(10): 3380-3383. 